\title{
Synthesis and Structural Studies of NCN Diimine Palladium Pincer Complexes Bearing m-Terphenyl Scaffolds
}

\author{
Liqing Ma,${ }^{\dagger}$ Philip M. Imbesi,${ }^{\dagger}$ James B. Updegraff III,${ }^{\dagger}$ Allen D. Hunter, ${ }^{\ddagger}$ John D. Protasiewicz ${ }^{*}{ }^{\dagger}$
}

${ }^{\dagger}$ Department of Chemistry, Case Western Reserve University, 10900 Euclid Ave. Cleveland, OH 44106

${ }^{\ddagger}$ Department of Chemistry, Youngstown State University, One University Plaza, Youngstown, OH 44555 
NMR Spectra

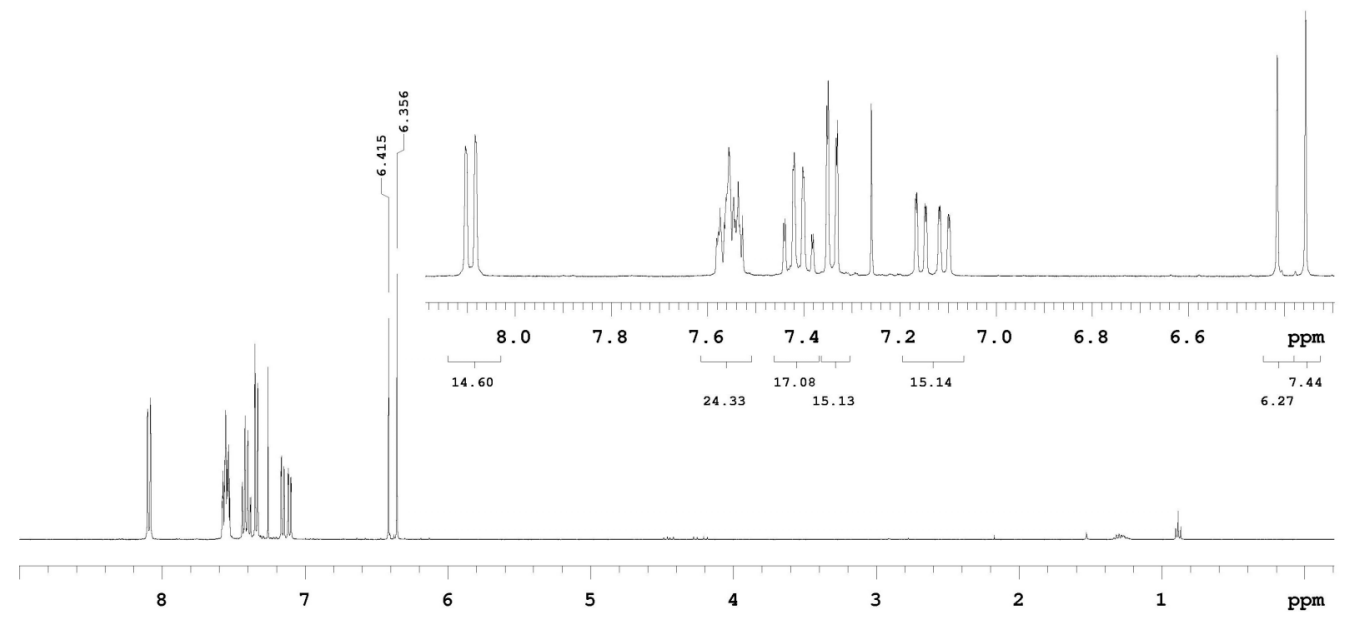

Figure S1. ${ }^{1} \mathrm{H} \mathrm{NMR}$ spectrum of $\mathbf{2} \mathbf{b}\left(\mathrm{CDCl}_{3}, 400 \mathrm{MHz}\right)$.

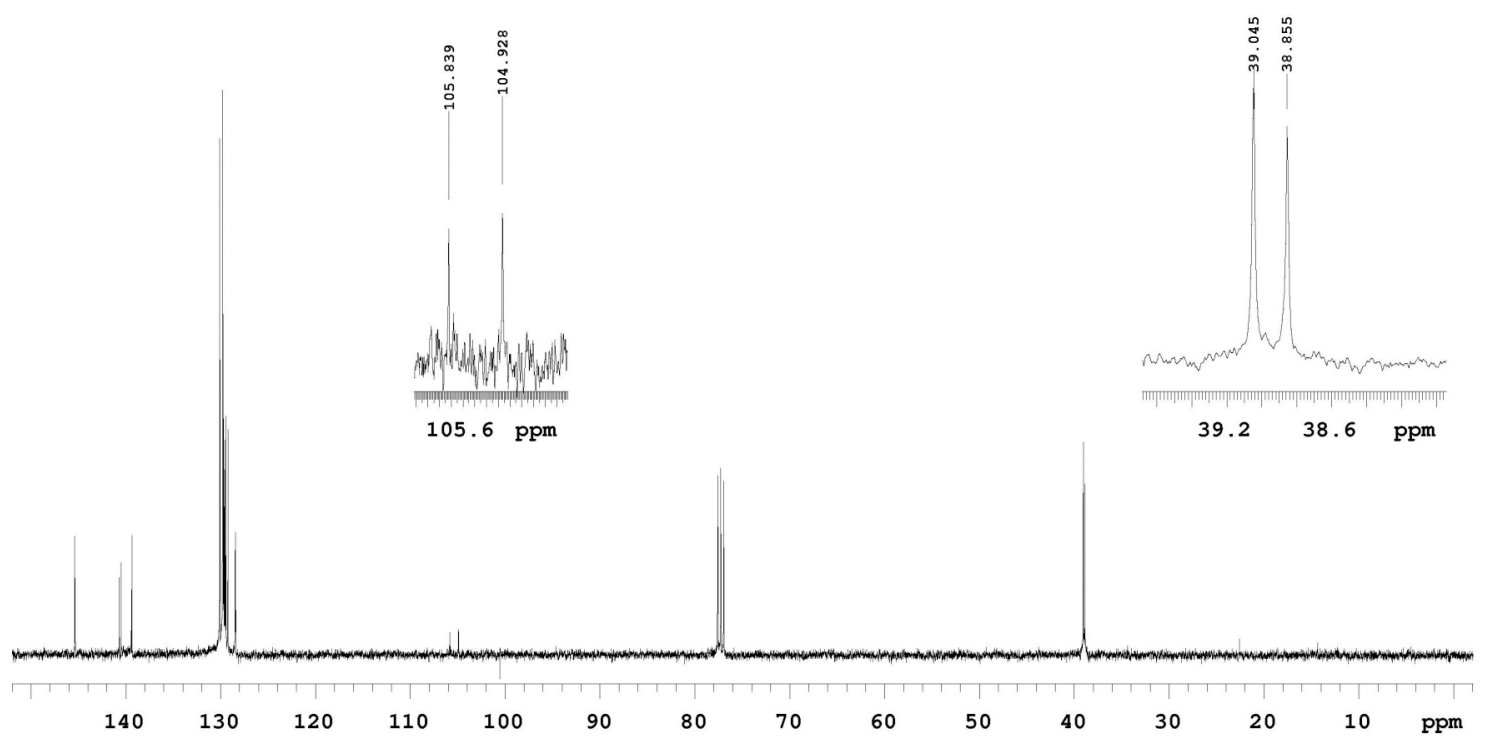

Figure S2. ${ }^{13} \mathrm{C}$ NMR spectrum of $\mathbf{2 b}\left(\mathrm{CDCl}_{3}, 100 \mathrm{MHz}\right)$. 


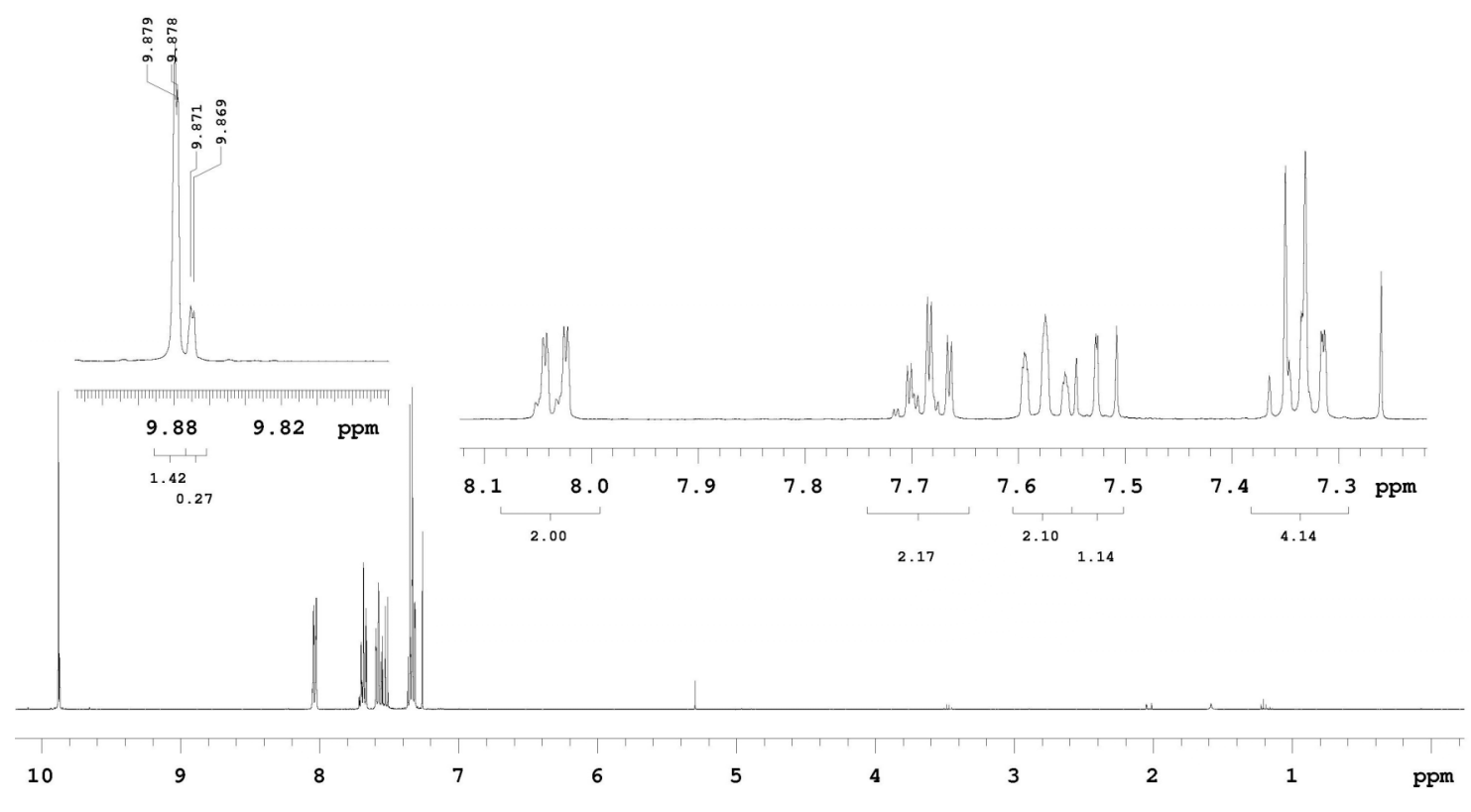

Figure S3. ${ }^{1} \mathrm{H}$ NMR spectrum of $\mathbf{3 b}\left(\mathrm{CDCl}_{3}, 400 \mathrm{MHz}\right)$.

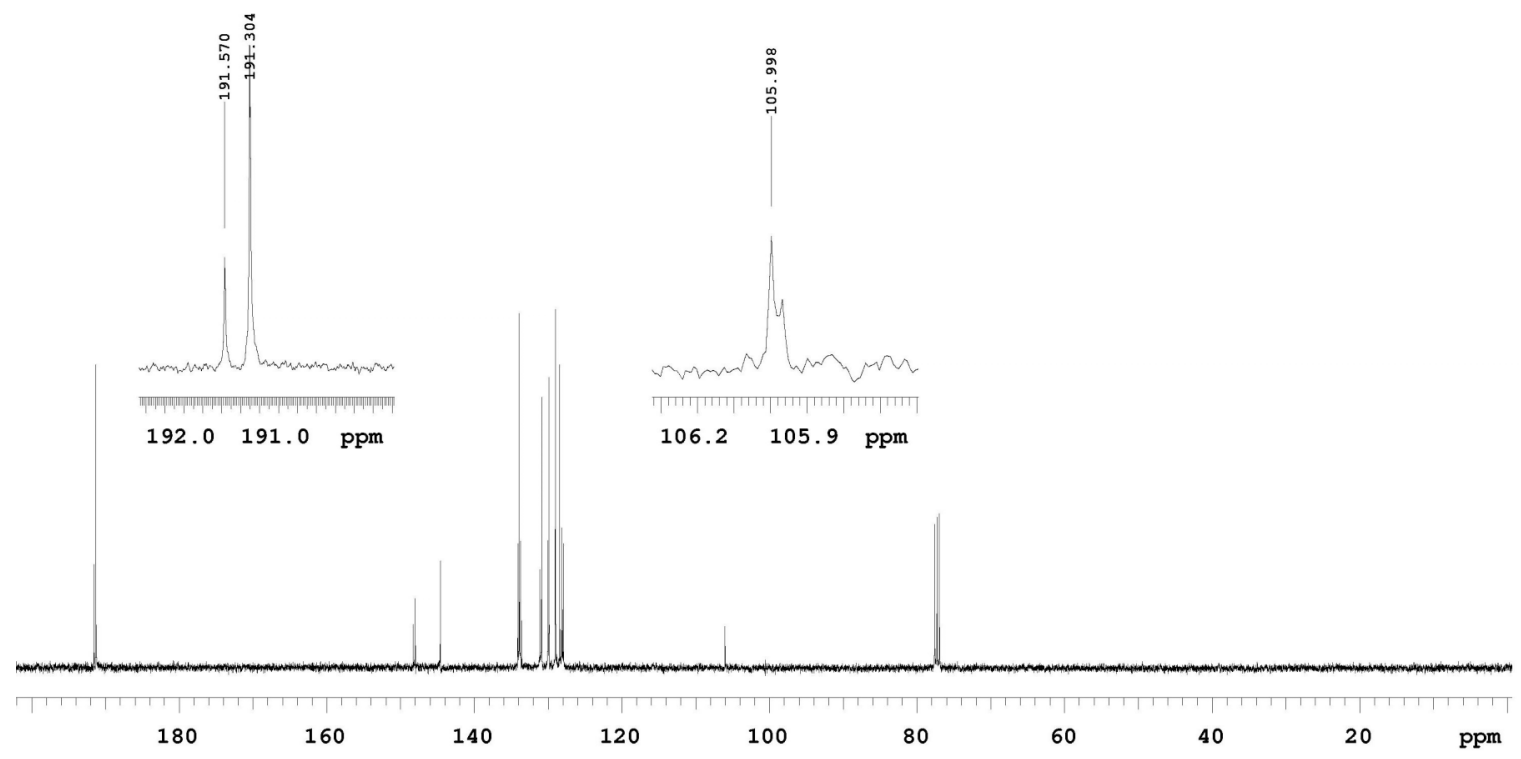

Figure S4. ${ }^{13} \mathrm{C}$ NMR spectrum of $\mathbf{3 b}\left(\mathrm{CDCl}_{3}, 100 \mathrm{MHz}\right)$. 


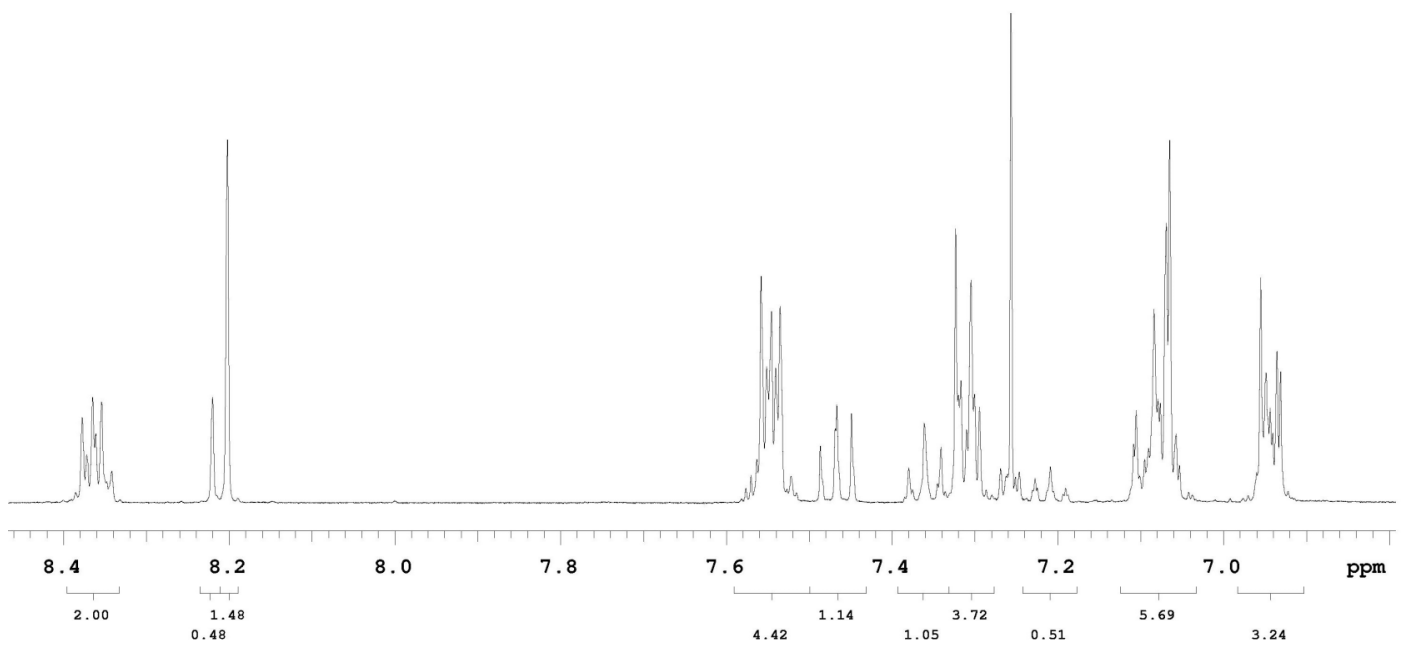

Figure S5. ${ }^{1} \mathrm{H}$ NMR spectrum of $\mathbf{4 b}\left(\mathrm{CDCl}_{3}, 400 \mathrm{MHz}\right)$.

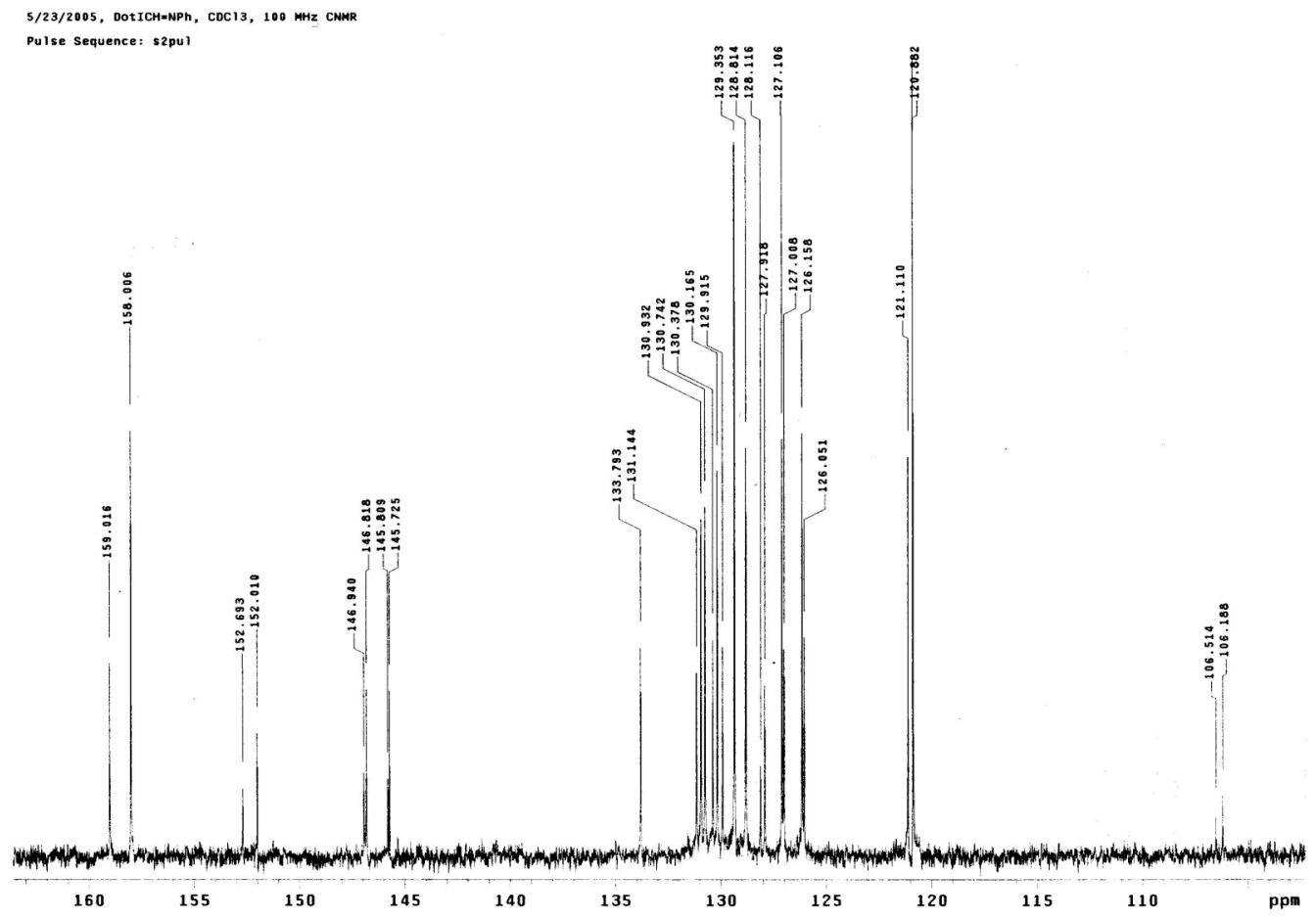

Figure S6. ${ }^{13} \mathrm{C}$ NMR spectrum of $\mathbf{4 b}\left(\mathrm{CDCl}_{3}, 100 \mathrm{MHz}\right)$. 


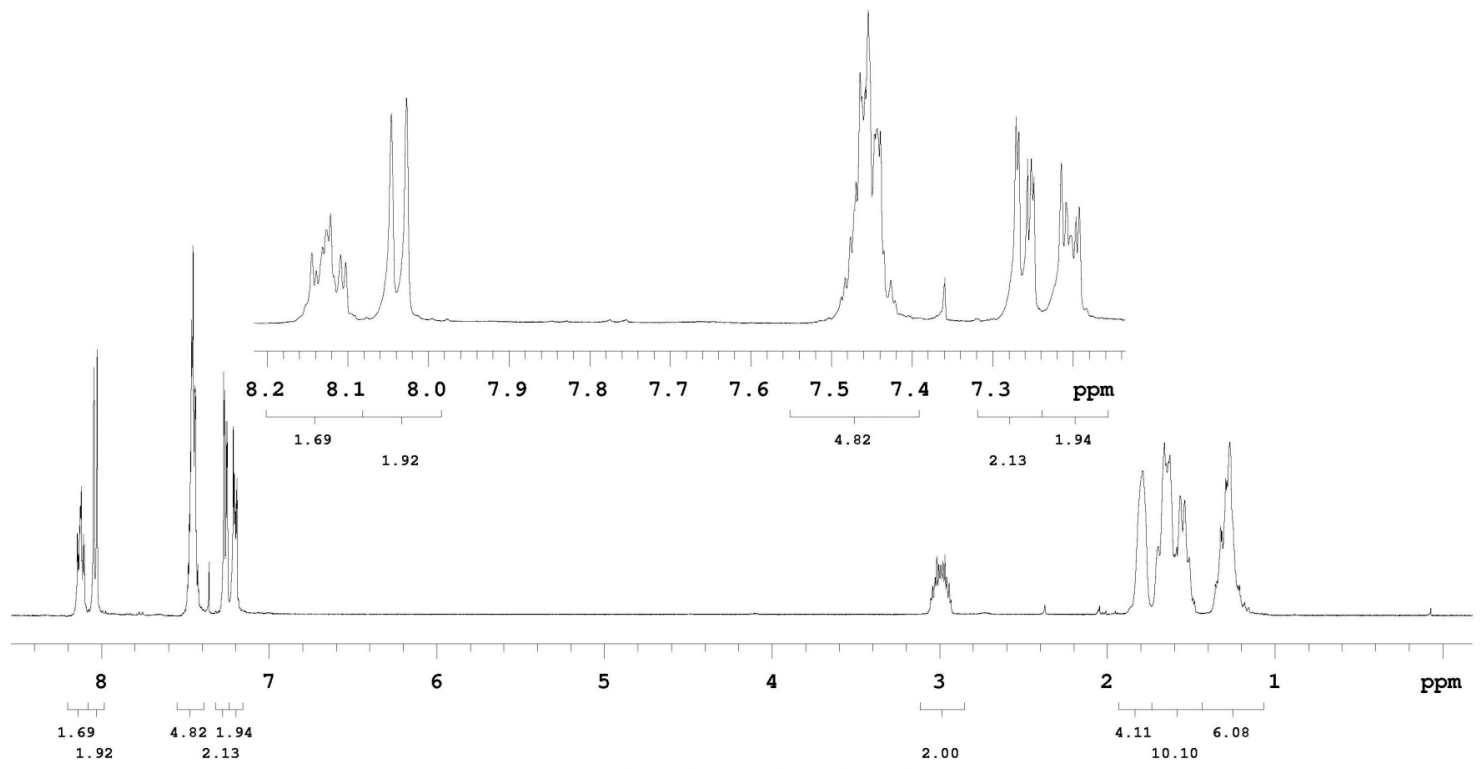

Figure S7. ${ }^{1} \mathrm{H}$ NMR spectrum of $\mathbf{5 b}\left(\mathrm{CDCl}_{3}, 400 \mathrm{MHz}\right)$.

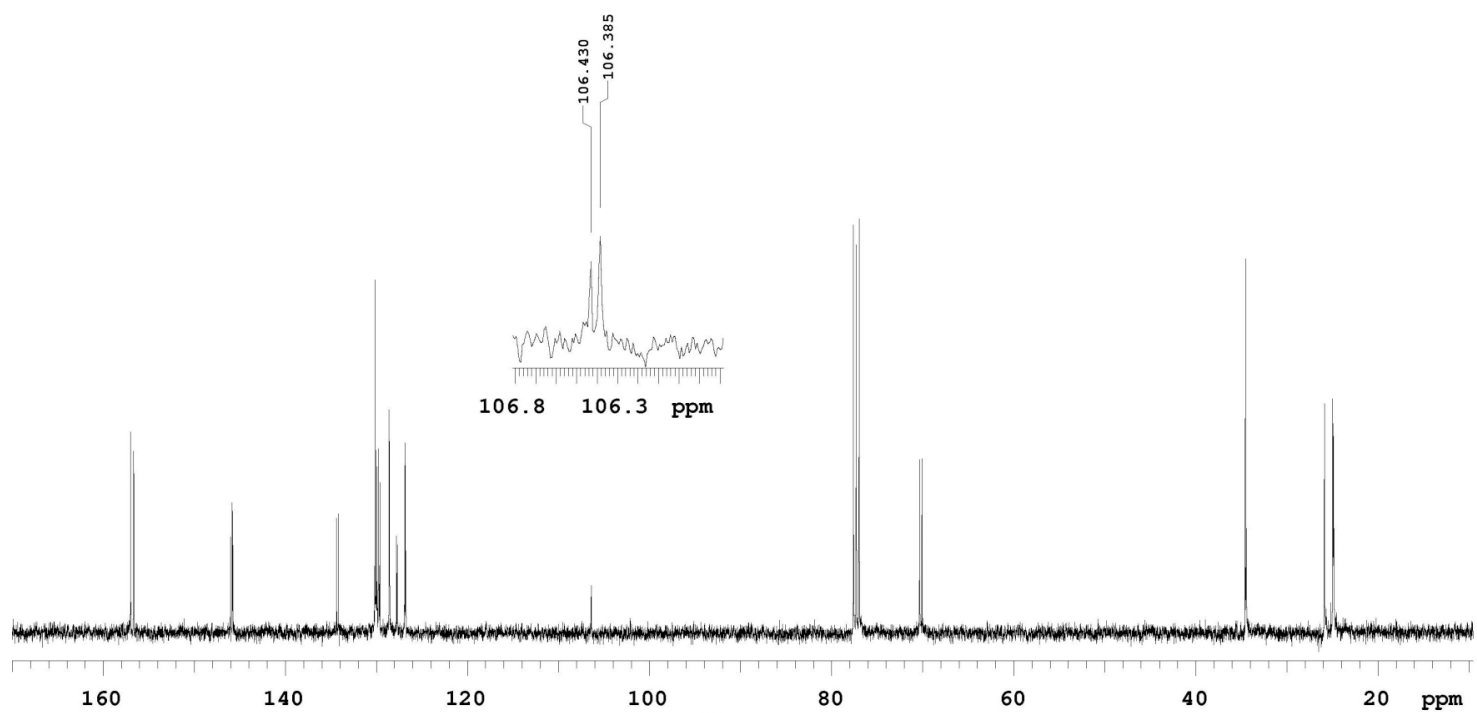

Figure S8. ${ }^{13} \mathrm{C}$ NMR spectrum of $\mathbf{5 b}\left(\mathrm{CDCl}_{3}, 100 \mathrm{MHz}\right)$. 


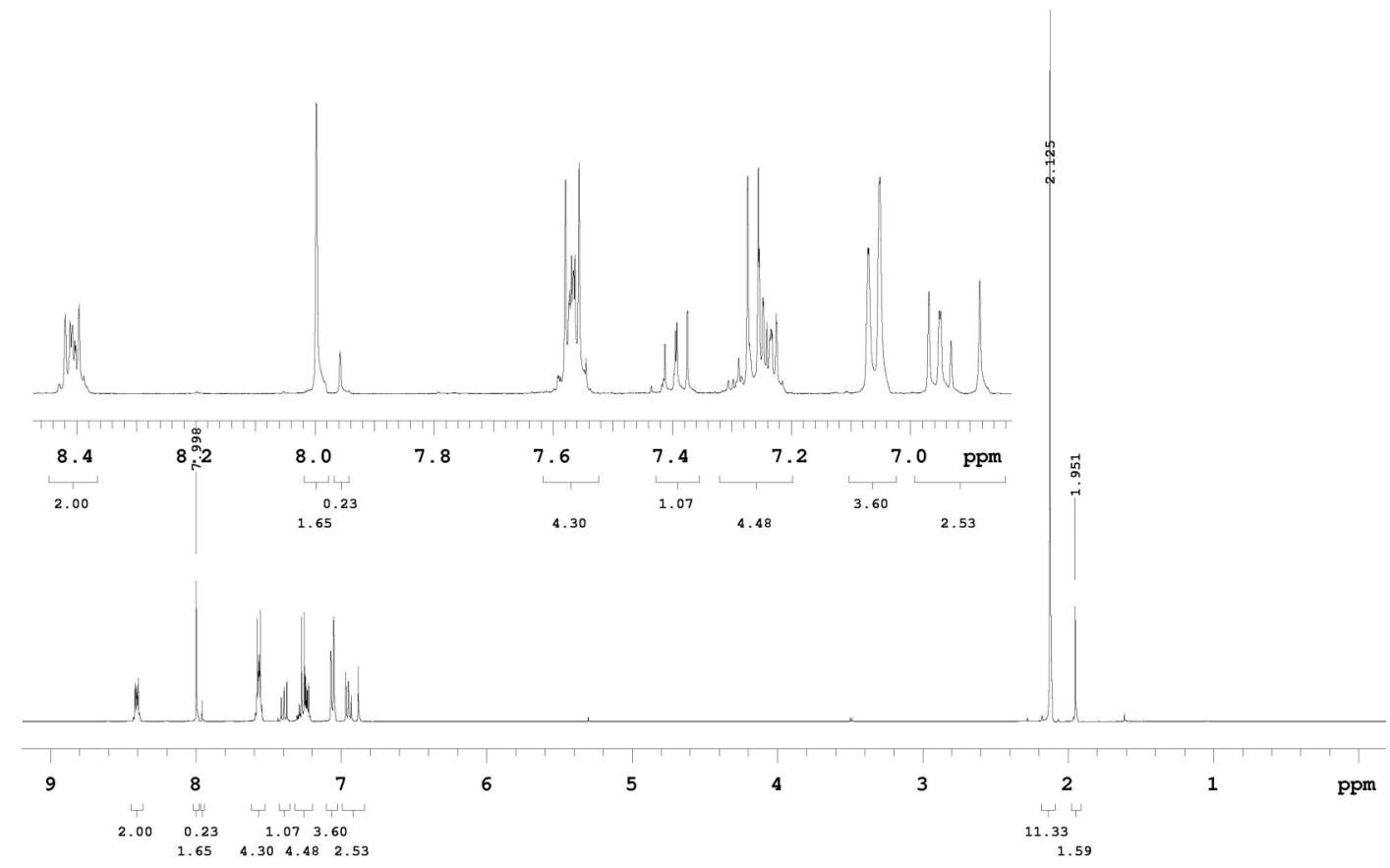

Figure S9. ${ }^{1} \mathrm{H}$ NMR spectrum of $\mathbf{6 b}\left(\mathrm{CDCl}_{3}, 400 \mathrm{MHz}\right)$.

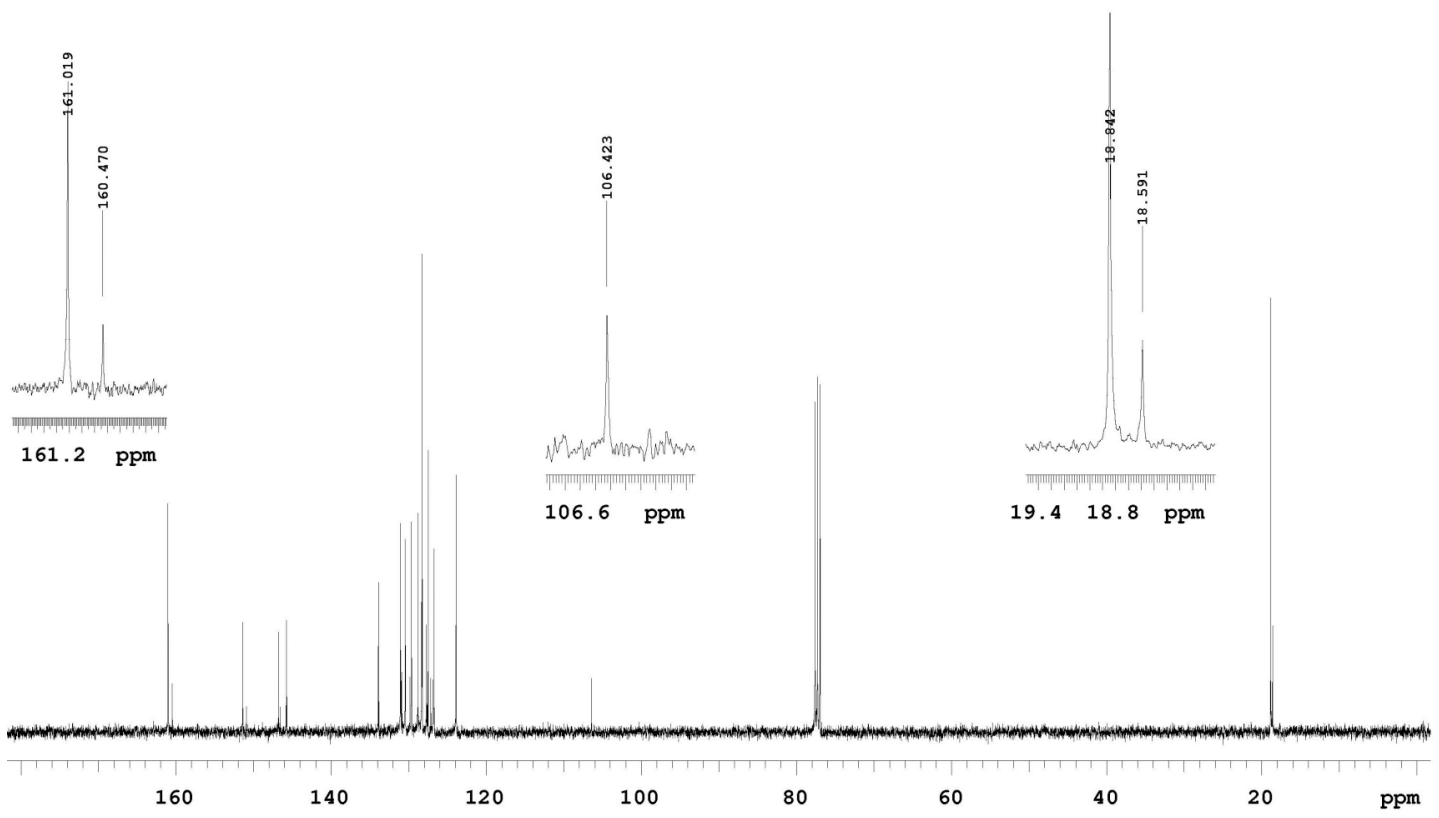

Figure S10. ${ }^{13} \mathrm{C}$ NMR spectrum of $\mathbf{6 b}\left(\mathrm{CDCl}_{3}, 100 \mathrm{MHz}\right)$. 


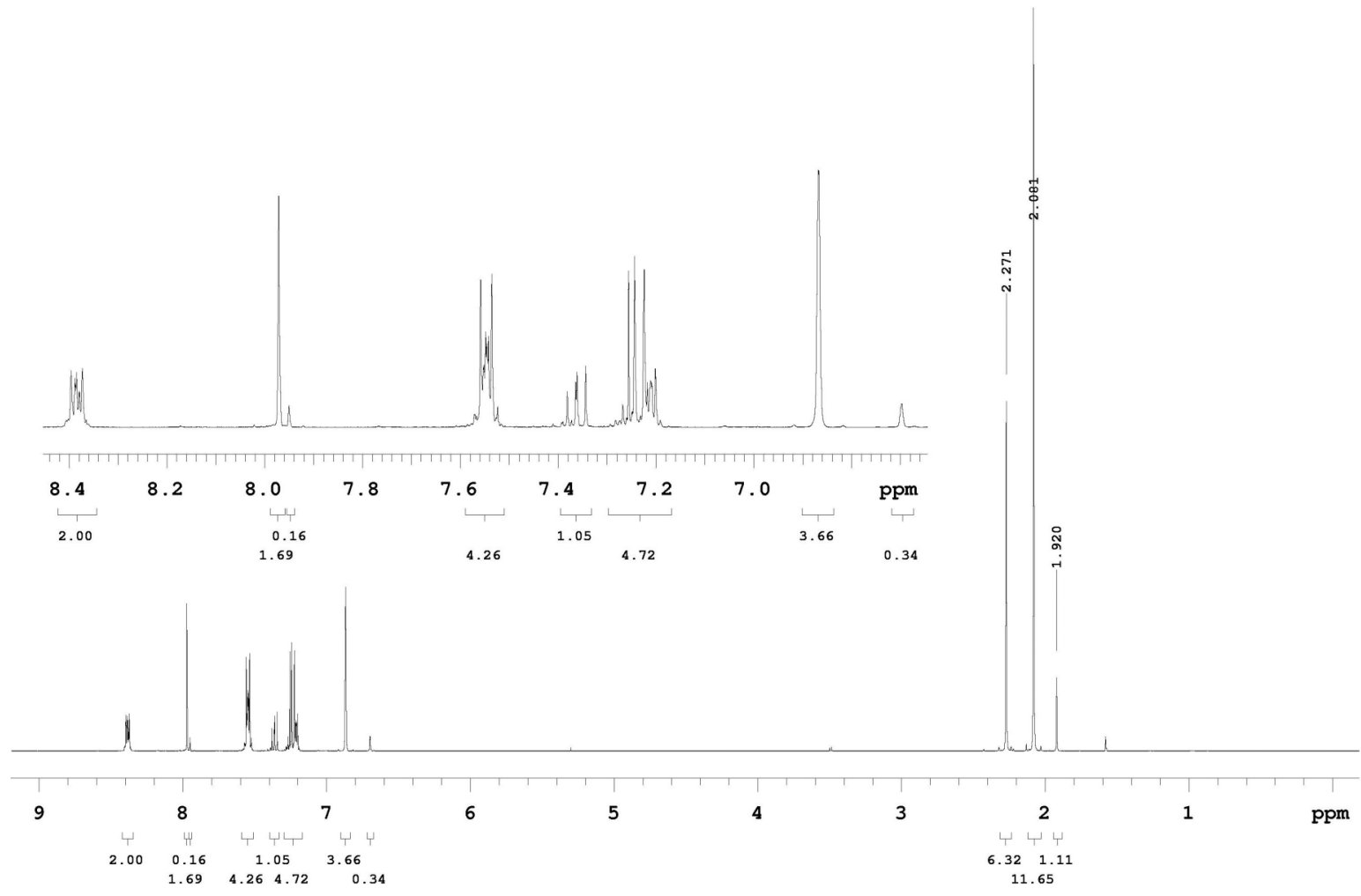

Figure S11. ${ }^{1} \mathrm{H}$ NMR spectrum of $\mathbf{7 b}\left(\mathrm{CDCl}_{3}, 400 \mathrm{MHz}\right)$.

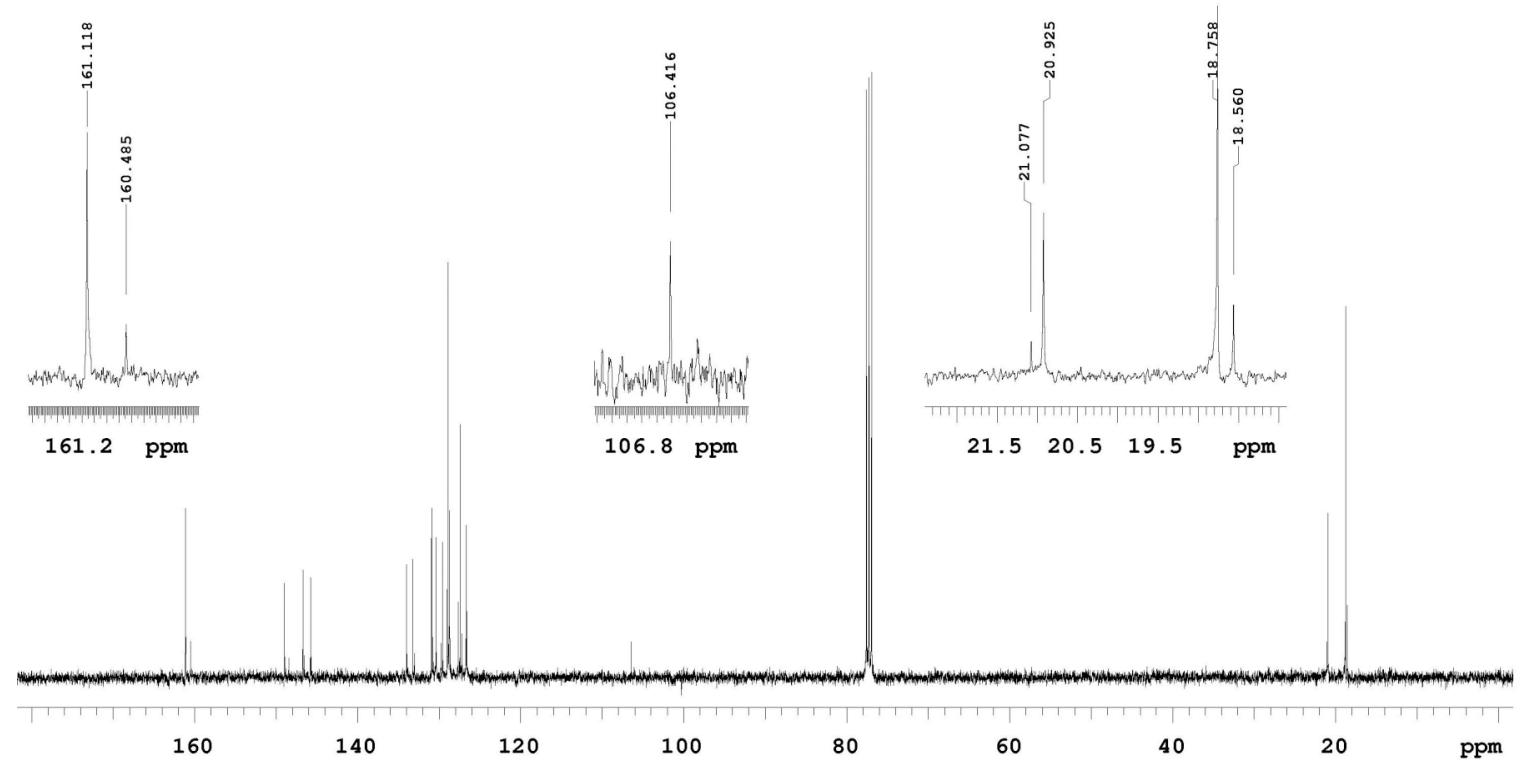

Figure S12. ${ }^{13} \mathrm{C}$ NMR spectrum of $\mathbf{7 b}\left(\mathrm{CDCl}_{3}, 100 \mathrm{MHz}\right)$. 


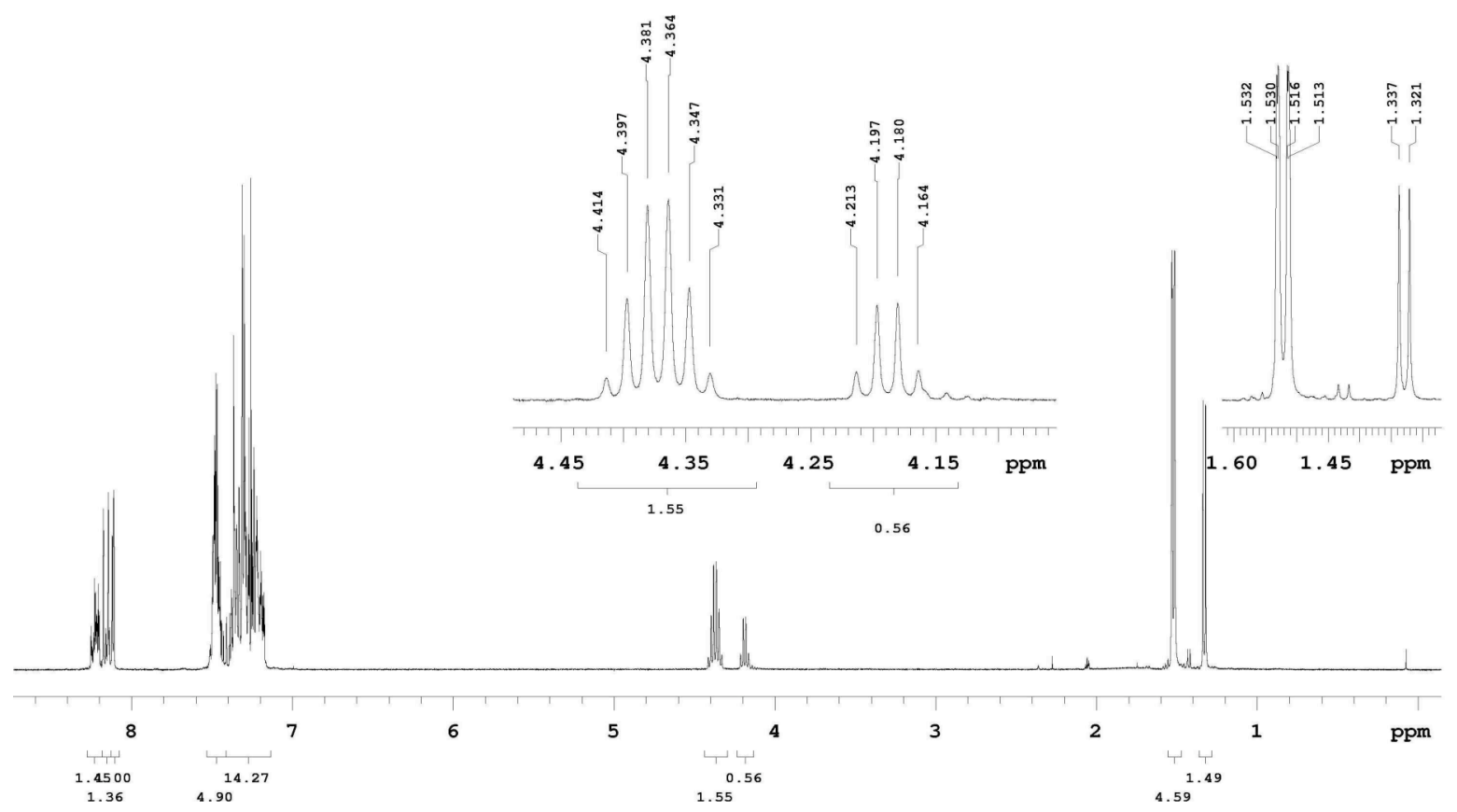

Figure S13. ${ }^{1} \mathrm{H}$ NMR spectrum $\left(\mathrm{CDCl}_{3}, 400 \mathrm{MHz}\right)$ for ligand 8.

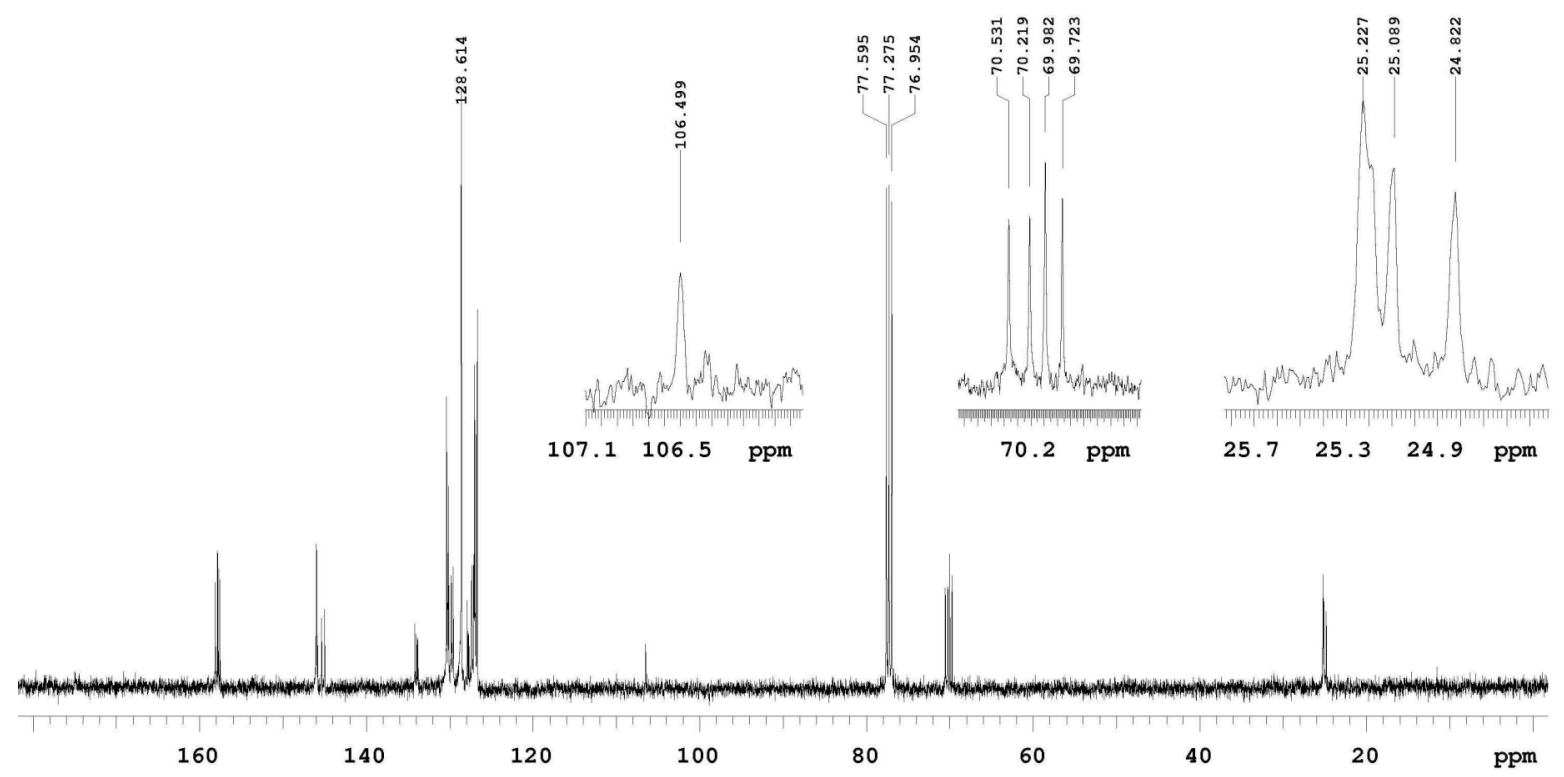

Figure S14. ${ }^{13} \mathrm{C}$ NMR spectrum $\left(\mathrm{CDCl}_{3}, 100 \mathrm{MHz}\right)$ for ligand 8 . 


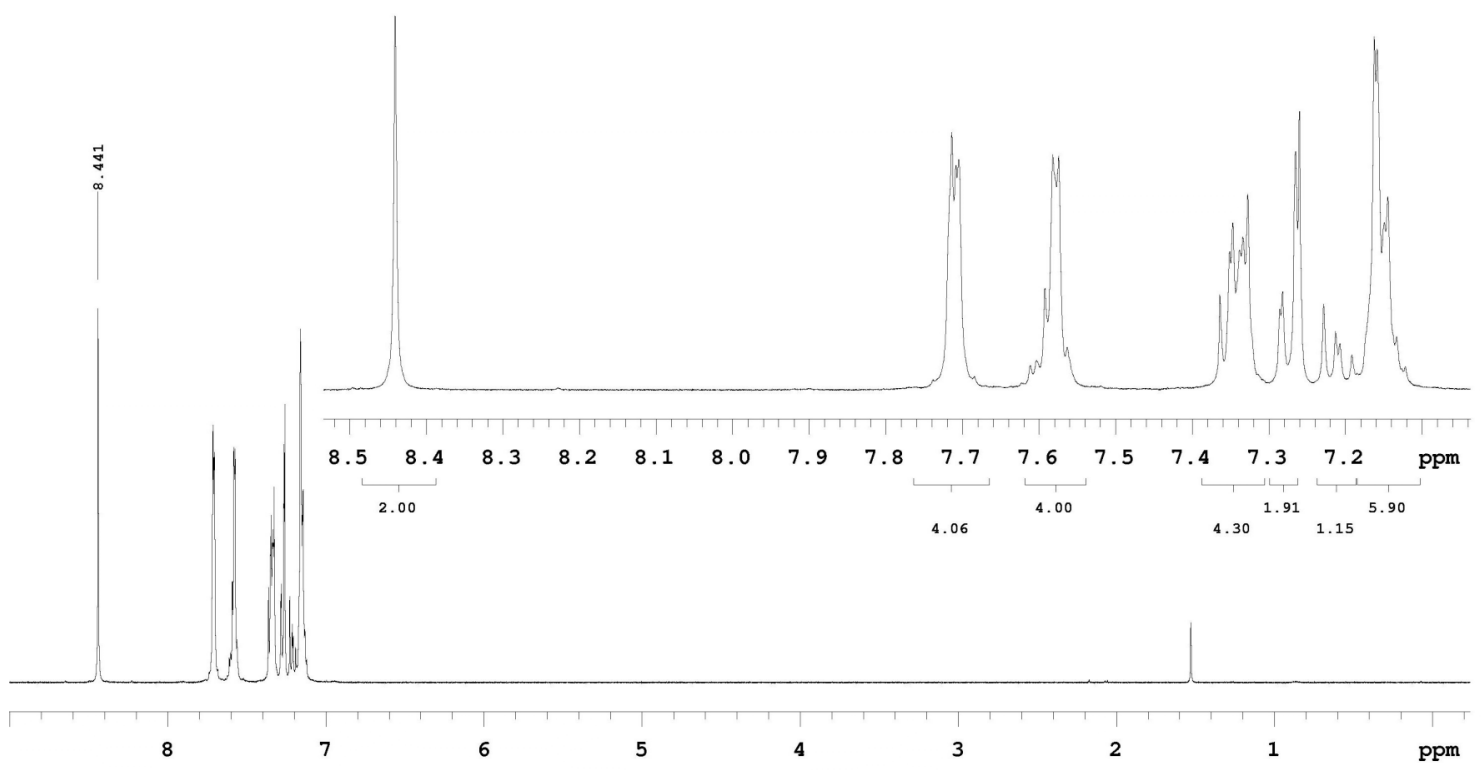

Figure S15. ${ }^{1} \mathrm{H}$ NMR spectrum of $9\left(\mathrm{CDCl}_{3}, 400 \mathrm{MHz}\right)$.

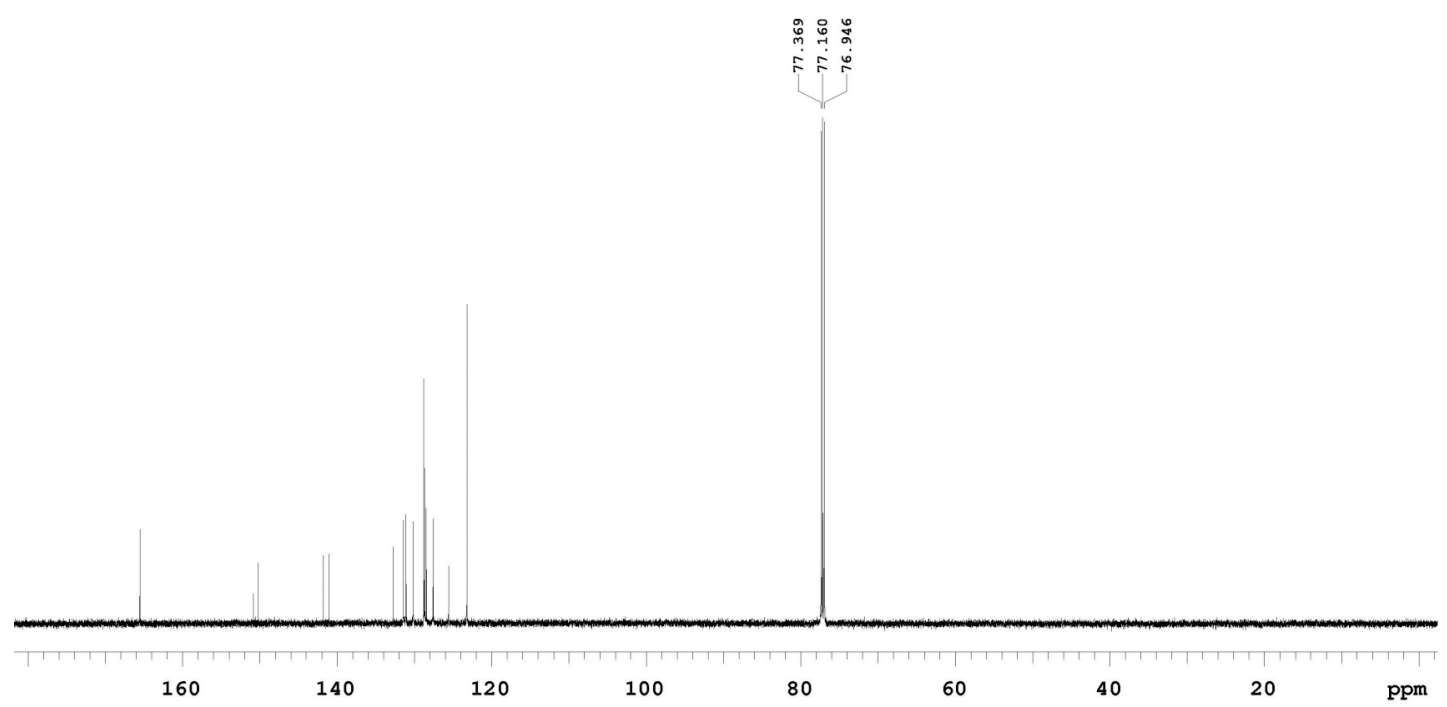

Figure S16. ${ }^{13} \mathrm{C}$ NMR spectrum of $9\left(\mathrm{CDCl}_{3}, 100 \mathrm{MHz}\right)$. 


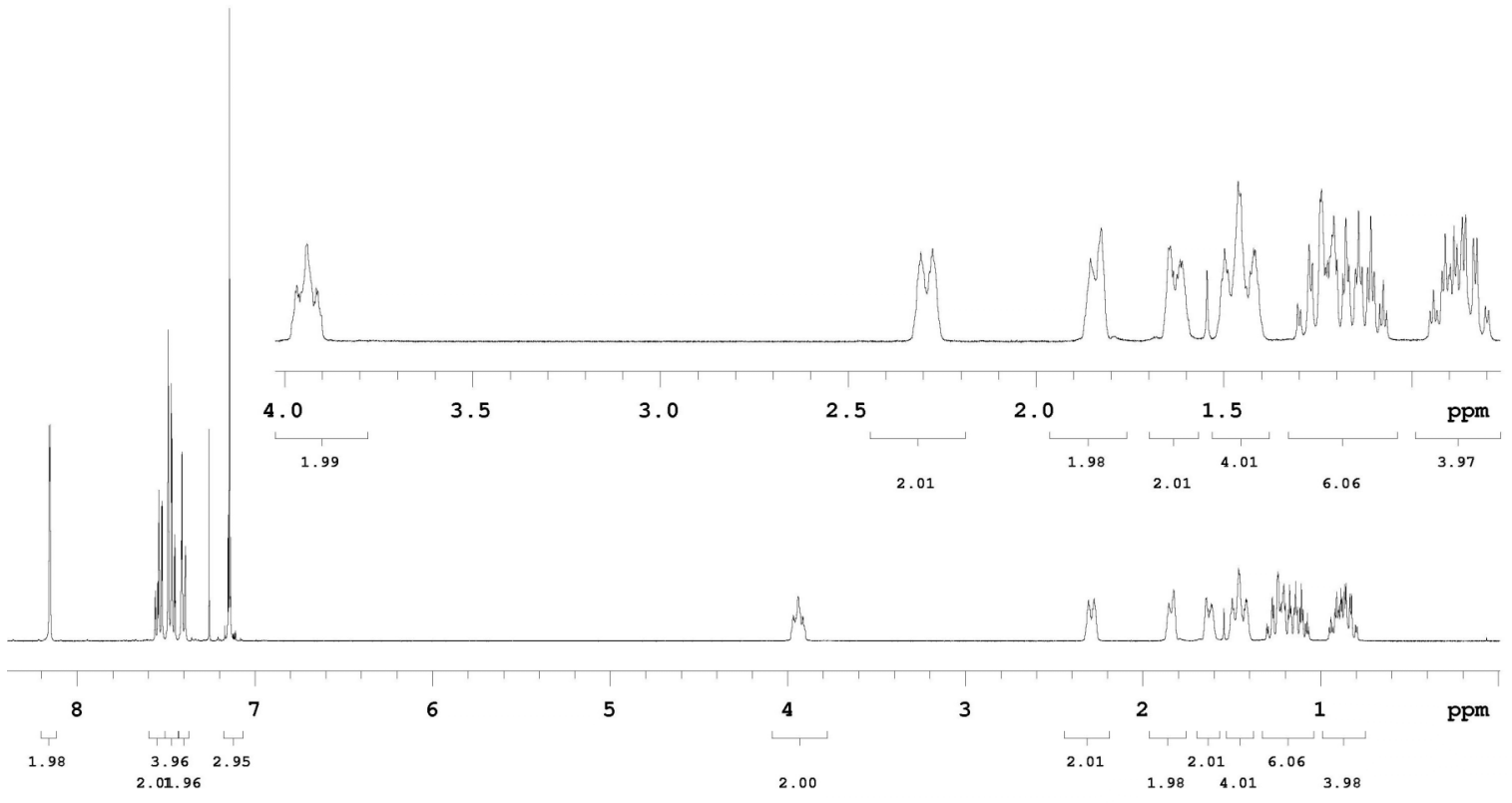

Figure S17. ${ }^{1} \mathrm{H}$ NMR spectrum of $\mathbf{1 0}\left(\mathrm{CDCl}_{3}, 400 \mathrm{MHz}\right)$.

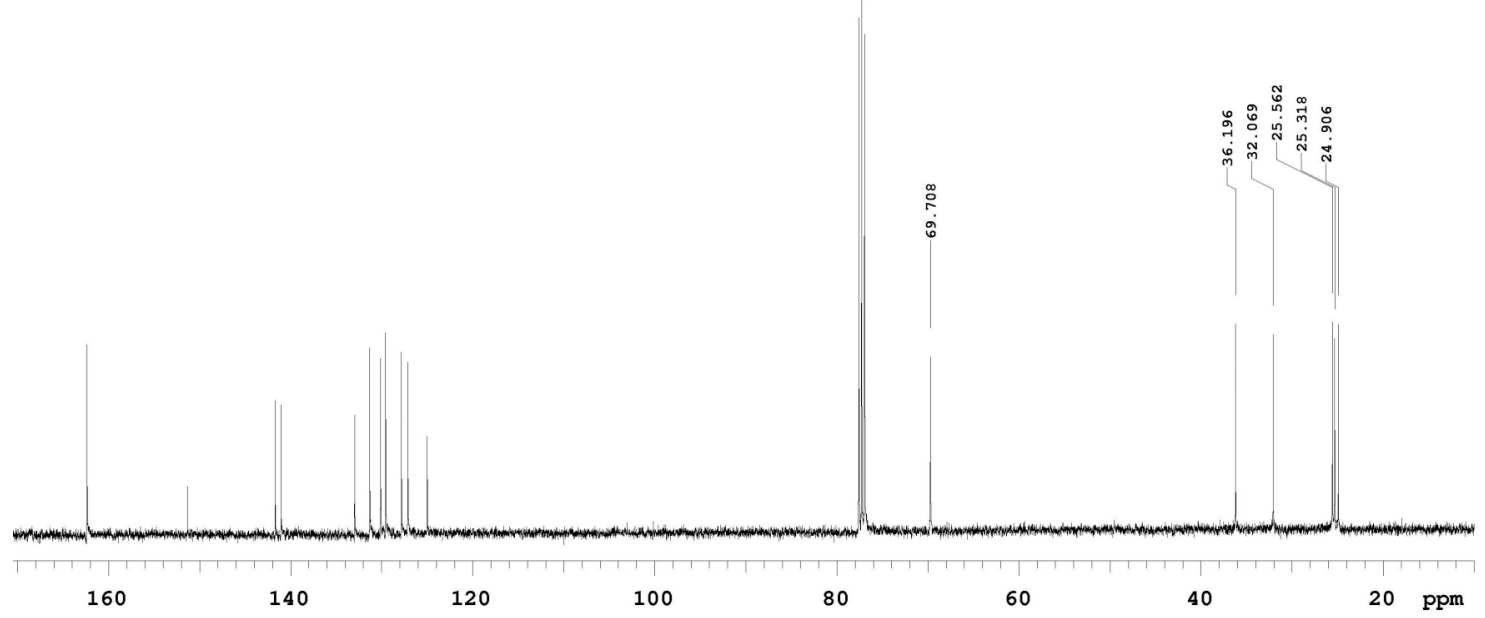

Figure S18. ${ }^{13} \mathrm{C}$ NMR spectrum of $\mathbf{1 0}\left(\mathrm{CDCl}_{3}, 100 \mathrm{MHz}\right)$. 


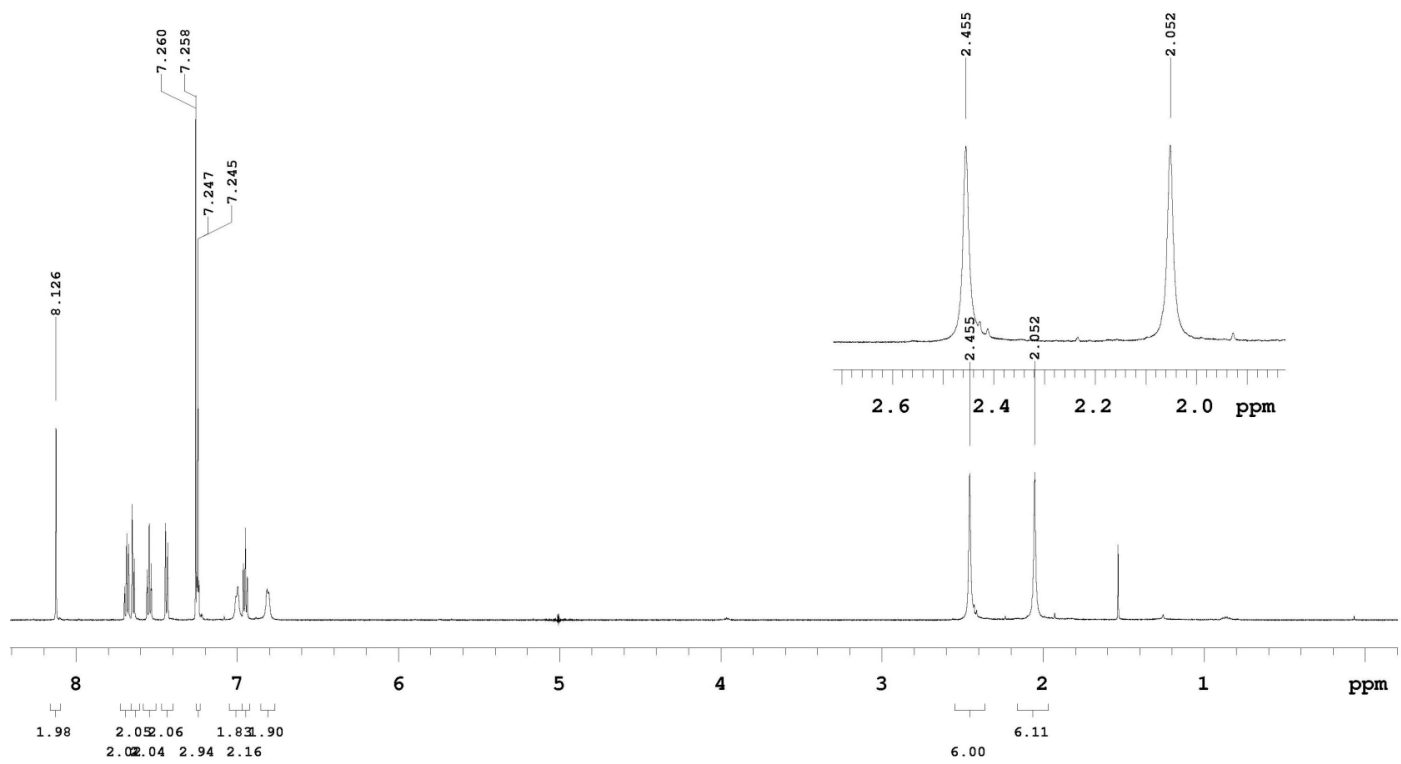

Figure S19. ${ }^{1} \mathrm{H}$ NMR spectrum of $\mathbf{1 1}\left(\mathrm{CDCl}_{3}, 600 \mathrm{MHz}\right)$.

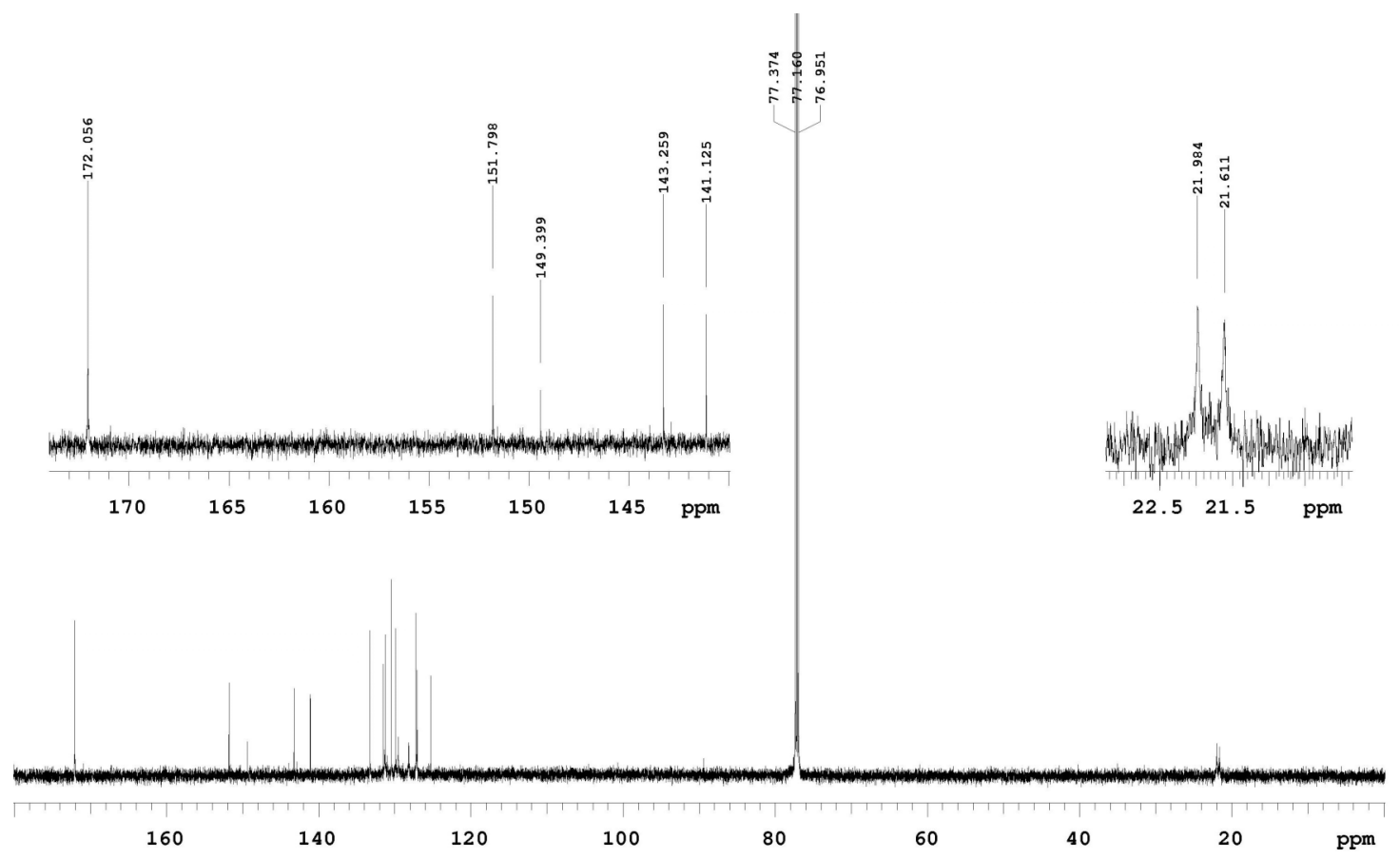

Figure S20. ${ }^{13} \mathrm{C}$ NMR spectrum of $\mathbf{1 1}\left(\mathrm{CDCl}_{3}, 100 \mathrm{MHz}\right)$. 


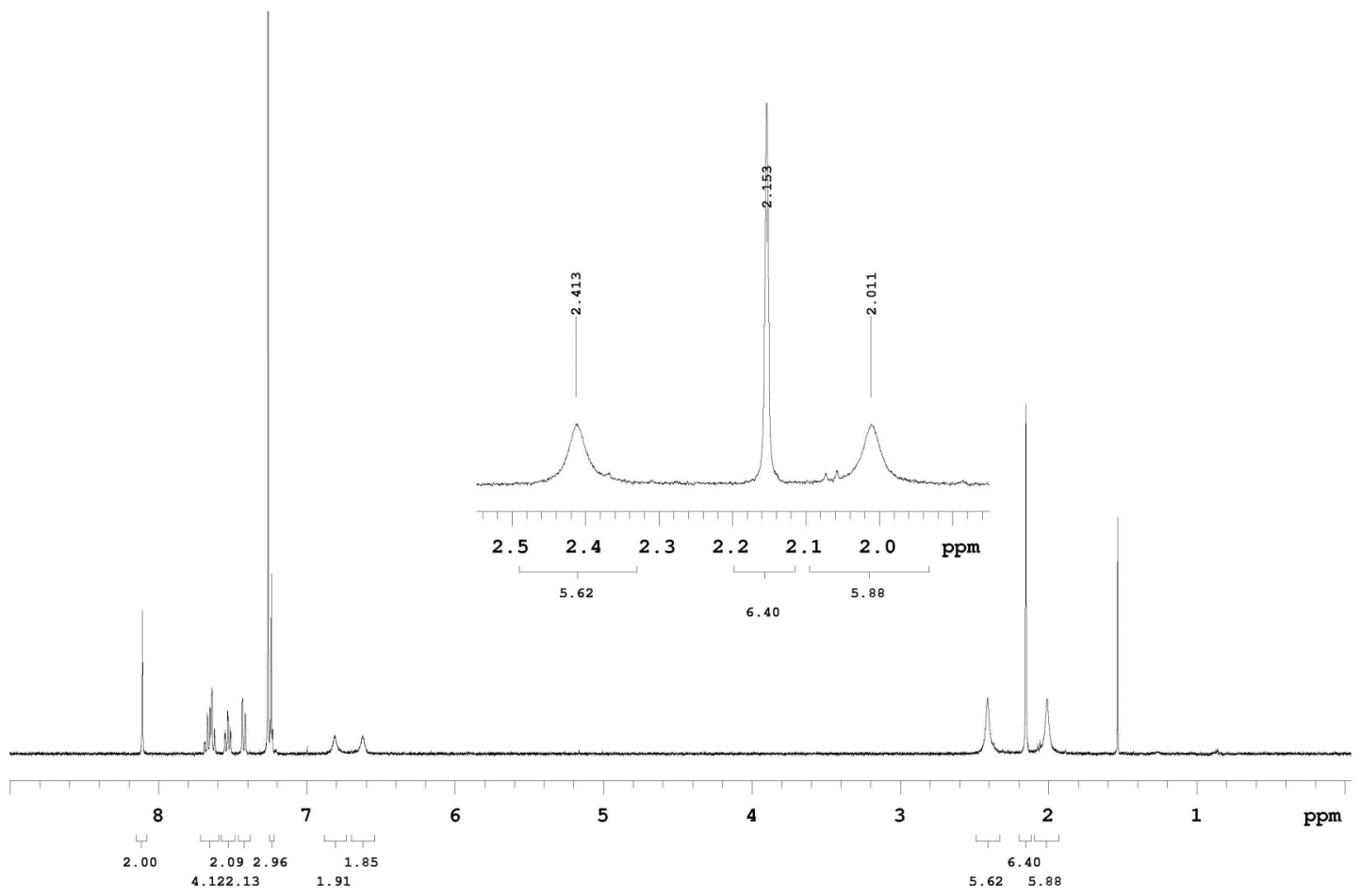

Figure S21. ${ }^{1} \mathrm{H}$ NMR spectrum of $12\left(\mathrm{CDCl}_{3}, 400 \mathrm{MHz}\right)$.

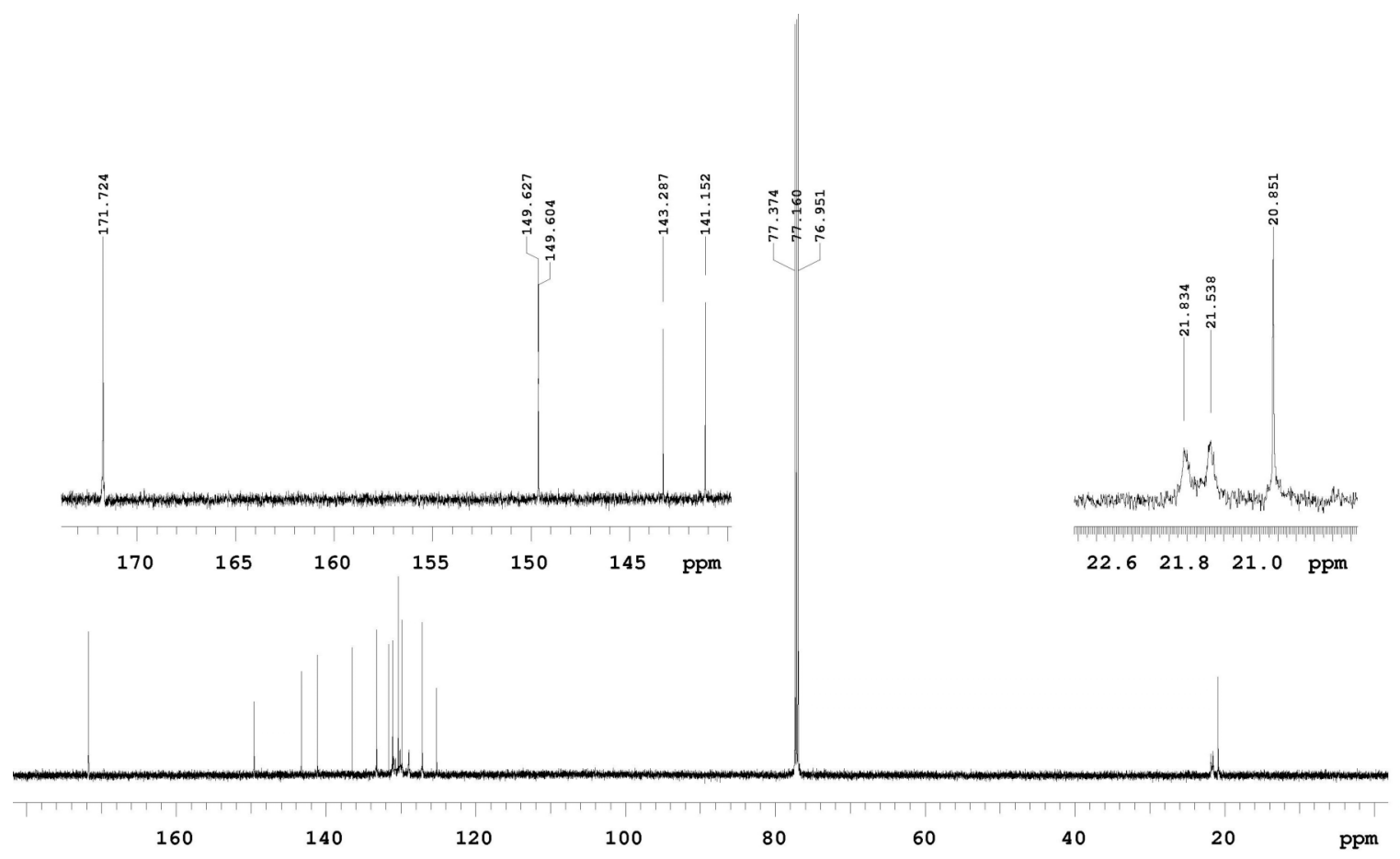

Figure S22. ${ }^{13} \mathrm{C}$ NMR spectrum of $12\left(\mathrm{CDCl}_{3}, 100 \mathrm{MHz}\right)$. 


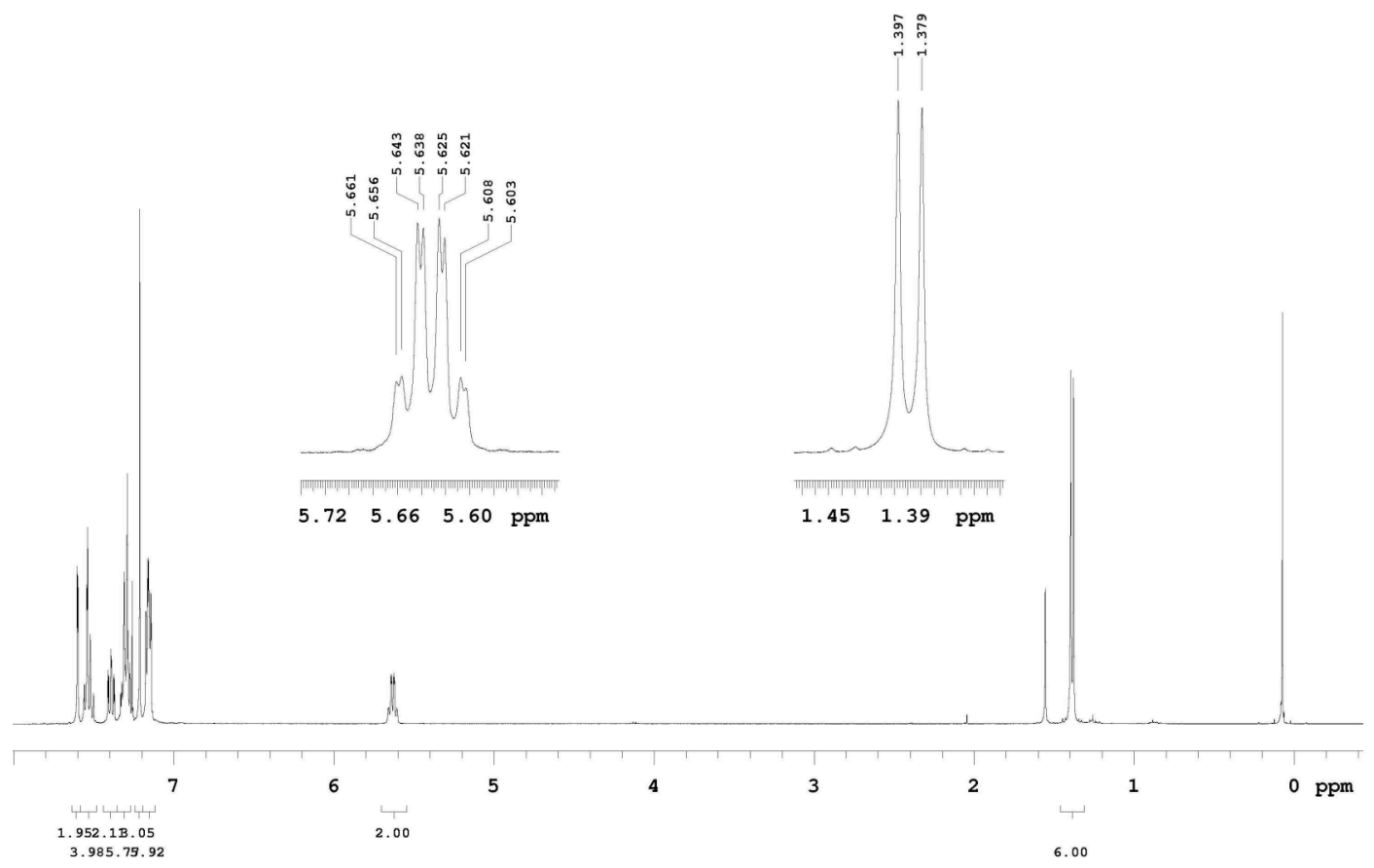

Figure S23. ${ }^{1} \mathrm{H}$ NMR spectrum of $\mathbf{1 3 a}\left(\mathrm{CDCl}_{3}, 400 \mathrm{MHz}\right)$.

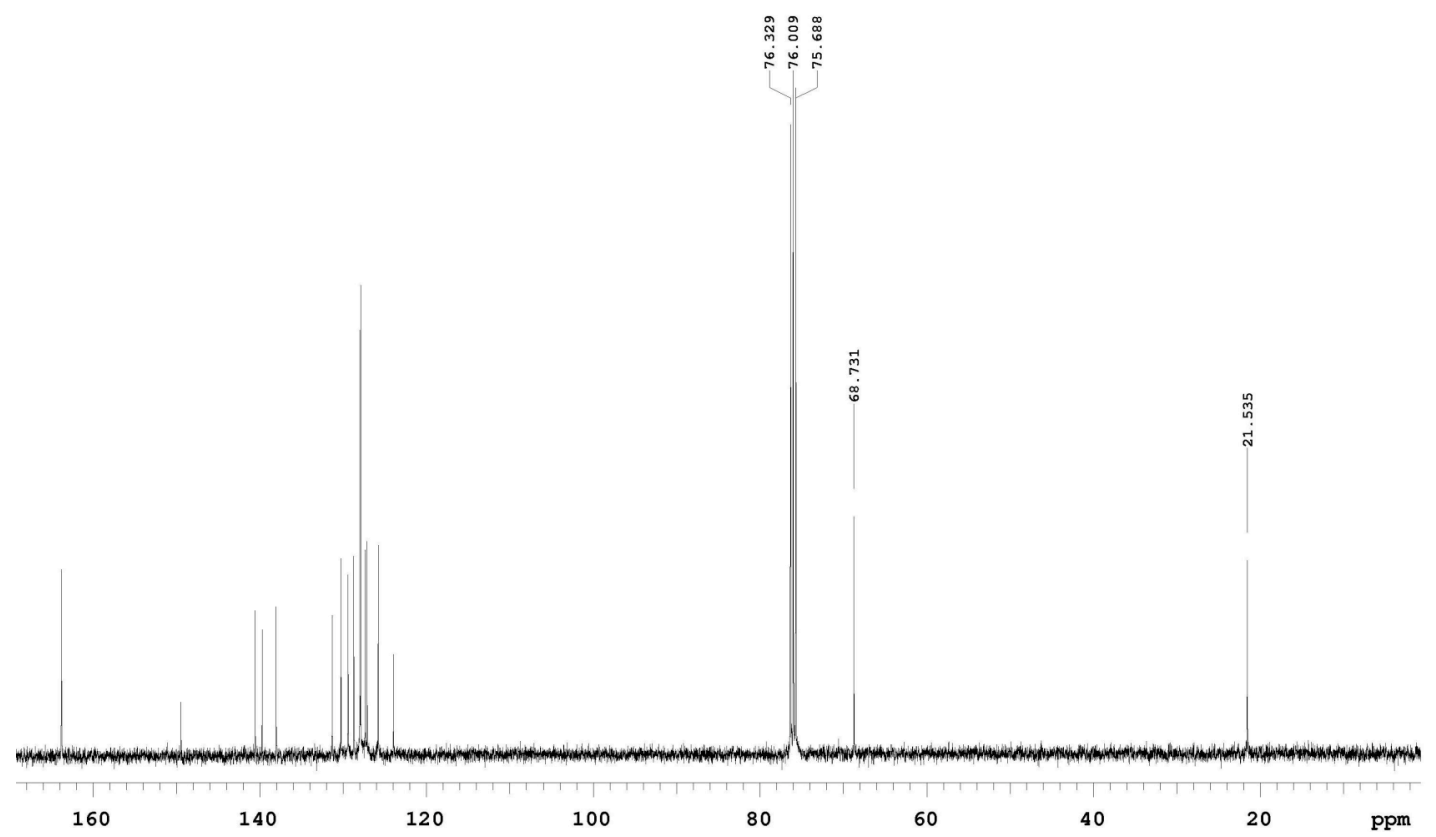

Figure S24. ${ }^{13} \mathrm{C}$ NMR spectrum of 13a $\left(\mathrm{CDCl}_{3}, 100 \mathrm{MHz}\right)$. 


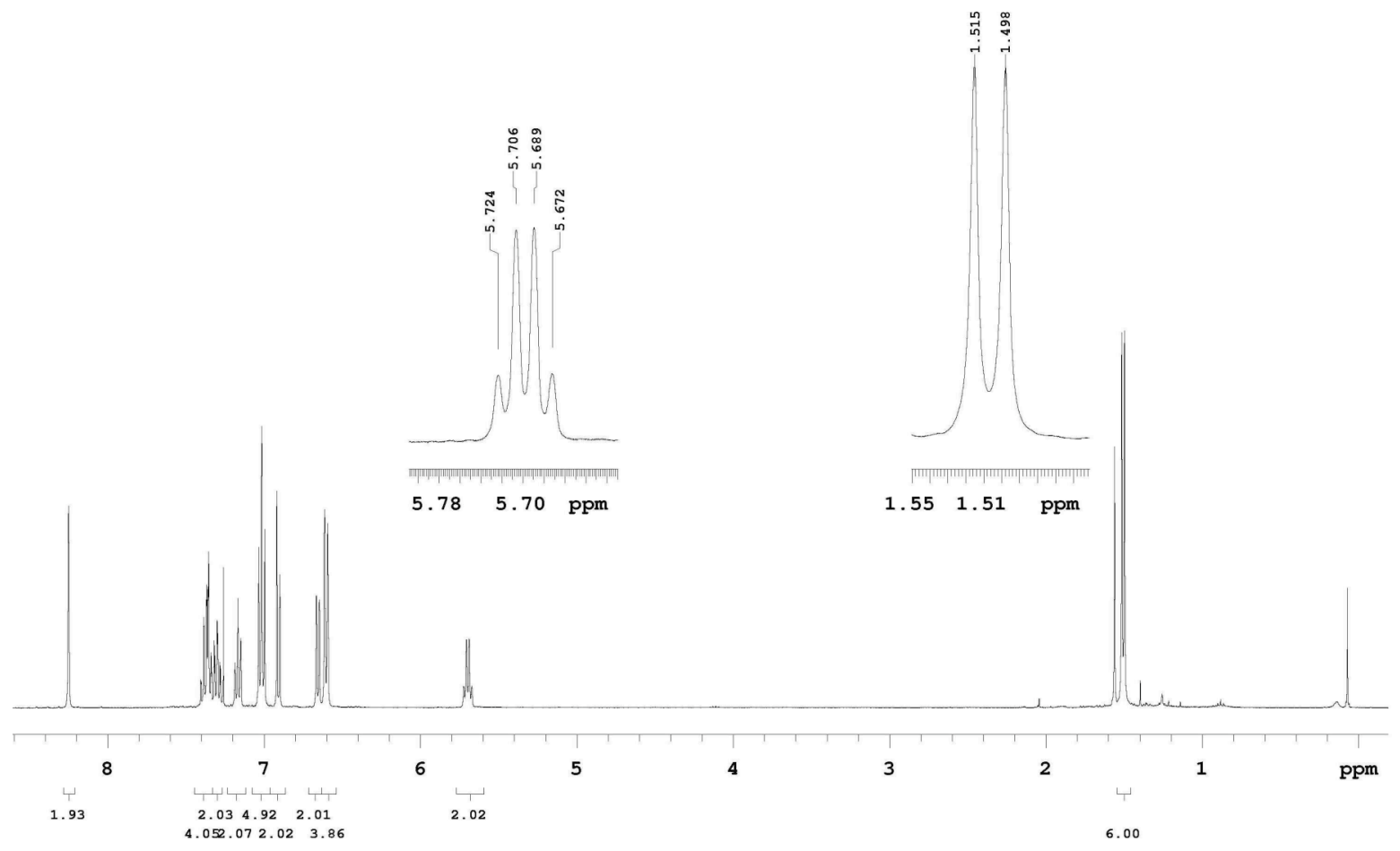

Figure S25. ${ }^{1} \mathrm{H}$ NMR spectrum of $\mathbf{1 3 b}\left(\mathrm{CDCl}_{3}, 400 \mathrm{MHz}\right)$.

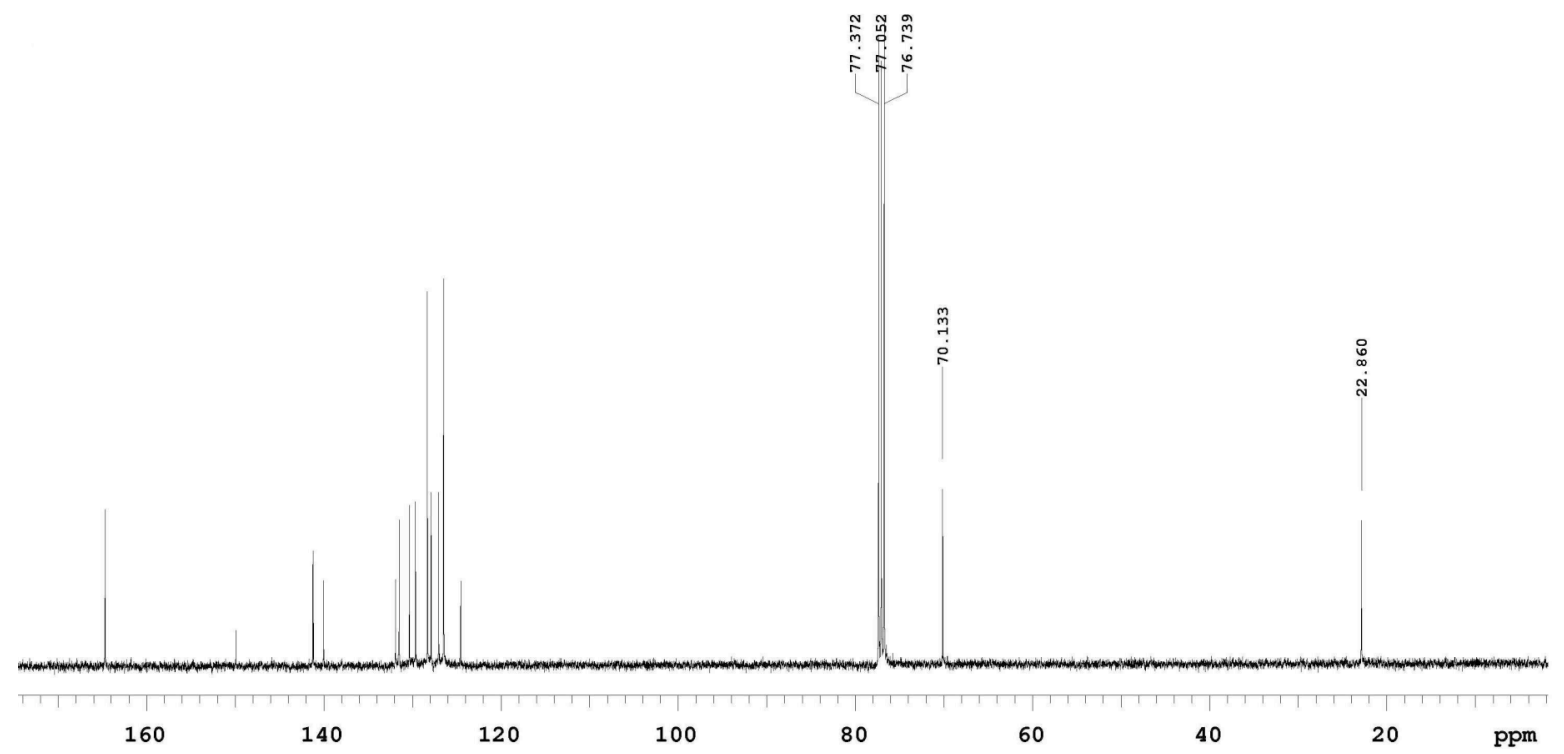

Figure S26. ${ }^{13} \mathrm{C}$ NMR spectrum of $\mathbf{1 3 b}\left(\mathrm{CDCl}_{3}, 100 \mathrm{MHz}\right)$. 